\title{
SaaS 2.0 onward! Business process management as an on-demand capability-Interview with Ismael Ghalimi of Intalio
}

\begin{abstract}
Ismael Ghalimi
is a passionate entrepreneur and fervent industry observer, founder and CEO of Intalio, creator of BPMI.org, initiator of the BPM 2.0 movement, producer of the Office 2.0 Conference and designer of the Redux Model 1 . Ismael is an adviser to several high-tech companies, including 3TERA, AdventNet (a.k.a. Zoho), Diigo, EchoSign, EveryTrail, G.ho.st, Move \& Play and Open IT Works.
\end{abstract}

\section{Keywords: business process management, open source, enterprise content management, workflow management, business process modeling notation, office 2.0}

\begin{abstract}
Ismael Ghalimi co-founded Intalio back in 1999. Since then Intalio has become the leader in open source business process management (BPM). In this interview with Ismael, Michael Moon discusses the history of BPM and some of the problems in the industry. They also talk about how software-as-a-service acts as both a disruptive technology and an enabling ecosystem. Michael asks Ismael about the role of federated work-management dashboards and process orchestration for digital supply chains. They wind up by summarizing critical factors for putting together a taskforce for large BPM projects.
\end{abstract}

Journal of Digital Asset Management (2008) 4, 252-259. doi:10.1057/dam.2008.37

MM: Ismael, let's start with a little background in terms of you and Intalio.

IG: My name is Ismael Ghalimi. I am the CEO of Intalio, and we are an open source business process management (BPM) software company. We sell a BPM platform that allows larger organizations and governments to automate fairly complex business processes that tend to change fairly often.

We've got a strong focus on government as well as financial services, and the telecommunications services industry. Together, they account for about two-thirds of our business.

We're based in Palo Alto, California. I live there with my wife and our 1-year-old baby girl. In my free time, I'm a private pilot, and organize a little conference in San Francisco called the "Office 2.0 " conference. It's a gathering of about 600 people that meet every year for two days, and talk about how to do office productivity work in the cloud, using only online applications and storing all the data online. It's kind of a real-life experiment on using these Office 2.0 technologies.
MM: Would you explain for a moment what you mean by BPM? Perhaps get into a little of its history.

IG: Sure. Absolutely.

The acronym BPM - in the sense that it's used today - meaning "business process management," was, I believe, created in 2000. I think we were one of the very few companies and authors to use that acronym at that point. Prior to that, it was being used to refer to business process modeling or some variance of business process reengineering.

Really, this new wave of BPM is the use of technology to bridge the gap between business and IT. It enables corporations and governments to be a lot more agile in their management of complex business processes that tend to be more and more regulated, say, in the overall governance risk-management and compliance issues that large issues are faced with today. They tend to change quite often, and you're faced with the challenge of implementing that change in the organization.

There are business issues, as well as technical issues. The idea of the BPM system or the 
business process platforms is to bring IT and business together - to give them the same tools - and a common language to describe the business requirements and very rapidly turn them into active systems - systems of action. Then, to enable the business to make changes to them very rapidly without having to go through the traditional IT development processes that companies had to go through before.

MM: Ismael - part of the legacy of BPM lies in business process reengineering. Usually it has been a buzzword or a moniker to describe putting in some sort of enterprise contentmanagement and workflow-management system. Then, usually in the process of that, rationalizing or documenting some business logic by which these workers collaborate and interact. Is that a fair characterization?

IG: I think it's a very fair characterization of what happened in the market, and the bastardization of the BPM acronym or the concept for BPM. Essentially, that acronym became a little bit too popular - it was very hyped. Many different vendors came either from the traditional workflow automation space or from business flow vendors - or document-management system vendors. They banded together and called everything BPM.

My take on that is that if BPM is everything, then maybe it's not really anything.

Our view of BPM - our unique take on it — is that it's a much more radical technology. Maybe for the first time, it's giving to the enterprise a single tool - and a single way of representing processes and systems and the way people work that is usable both by the business people and by the IT people.

I could not think of any other tools - and I'm talking about a back-end development tool that would be usable by people who are fairly technical and also by people who are not technical at all.

MM: What makes it unique in terms of this next wave of business process management is - first of all - an IT services delivery framework of service-oriented architecture (SOA) and web services. And also, the BPM suite or platform being hosted and provisioned in as a service, as opposed to being deployed in the data center, for example. Is that fair?
IG: I think you're touching upon two very important points, there. One is indeed SOA. That's the enabling infrastructure to make BPM work on a large scale, and in a cost-effective manner. What we're doing today was simply not possible ten years ago, because the technology for web services - XML - the internet as a way to really connect multiple people and organizations today - just flat out did not exist.

The second thing that you're pointing to is a provisioning model where, indeed, you can get access to this technology on demand. You do not have to provision it in your data center. I think this is just an implementation detail — at least so far. I don't think that very many organizations are taking advantage of that today.

I also believe that we're going to get mainstream adoption and repeat users at a very large scale once people use it on demand. That's an area where we're making right now very significant investment. We actually just released our on-demand edition to half a dozen beta customers a couple of weeks ago.

MM: What do you anticipate?

IG: I think the technology just did not exist until very recently to make it work and to make it work at a large-enough scale. The products that were available on the market had been designed and architected with a model that essentially came from the client server era. It was just not suitable to be put online in a multi-tenant way, to make it very easy for customers to design and deploy these new processes in these hosted environments.

There were products that were designed in a much more monolithic manner. We were making a lot of assumptions about the underlying platform and the kind of components and technologies that would be required for it to work. It was just not suitable to be put online in such a fashion.

MM: In our interviews with other innovation leaders in this general area, they've shared with us that this new provisioning model - software as a service $(\mathrm{SaaS})$ - or process as a service (PaaS) - really leads to several very interesting developments.

One is that it breaks the mental mindset of enterprise software. That is to say if we were buying an ERP system that's got 50,000 
function points, you can compare function points from SAP — from Peoplesoft, from Oracle - compare and contrast the inherent capability. "What do we need?" Then make a technical decision of which platform best serves a particular need.

With this multi-tenant architecture and SaaS or PaaS, oftentimes you're using one-tenth of 1 per cent of the overall capability of a platform. This has a net effect of confusing or overwhelming buyers such that they need an equally complex methodology for determining their needs - as opposed to reverse engineering them from a standard set of function points. Would you concur with that, first of all?

IG: Yes. Very much so.

I think we as an industry - as an entity - make things a lot more complex than they should be, to confuse customers with either features they don't need or requirements that are just too significant to be fully implemented. I think that at the end of the day, this SaaS model - the main objective or main requirement is for it to lower the barrier to adoption - to make the technology as consumable by users as possible.

I also believe that what we're talking about - BPM SOA is new. It's based upon architecture elements that are new to customers. This requires, we believe, a little bit of training and education. Also, as much practice as possible.

Over the past eight years in the first wave of BPM software, we've seen that many of the implementations were conducted by the professional services group of the software vendor. So you'd have the vendor going to the customer, asking what problems they had at the business level. The customer would open up and describe the problem. Then the vendor would deploy an army of fairly expensive consultants to fix the problem, using the BPM technology of the vendor.

In some cases, it would fix the problem. Unfortunately, in many cases, it wouldn't. But that really was beside the point. Even when it would fix the problem, what would happen is that the customer would not learn anything about the way that solution was implemented. So, yes - the problem was fixed. But it was unclear whether it was fixed in a better way than could have been done with more traditional development tools.
Because the customer was not really involved in the implementation of that solution, there was no way to scale it up. There was no way to leverage this investment at a knowledge level, in order to solve the next problem that would arise at the business level.

We think that this technology - this BPM technology — to truly make an impact on the market - must be used by customers themselves. There must be a self-empowerment of the customer. They must adopt this technology themselves. Either doing it with their internal IT department or with system integration partners. But very importantly, they must not use the resources - the professional services resources - of the vendors. Otherwise, this knowledge transfer won't happen, and essentially you won't have any repeat sales within that account. That's something that we've seen again and again in the marketplace.

That's what has been slowing down the adoption of these technologies by customers in general. That's why we tend to flip the model over and to say, "Okay. First and foremost, Mr. Customer, you've got to come to training. You've got to learn the technology. We're not going to teach you about how to use our product. We're going to teach you about the standards that exist today for BPM. The standard way of modeling - of describing — business processes."

There's that great notation called the business process modeling notation or BPMN. For the first time, it's a standard way for customers and organizations to describe their business processes. It's usable by the business people as well as the IT people. Then there are lower-level standards - more technical standards to turn these models into applications and running systems - into systems of action.

I think standards here are playing a key role. Again, one of the reasons why adoption was actually slower than anticipated is that those standards could take quite a bit of time to mature. But now they're there. They're available. They're supported by several vendors especially the larger ones. We think for that reason, and also because SOA is now becoming the way of architecting new systems for the enterprise. We think the time has come for the BPM industry to really take off in a big way. 
MM: As I'd mentioned, there were two things that had emerged from our conversations. One is the emergence of the need for standards and the need for end-user organizations really directing and leading the automation process as opposed to paying professional services of a vendor to come in and create a black box.

The second thing that we've seen emerge around SaaS and as a provisioning of capabilities has been the social dimension of it - the essential critical need to develop a community of practitioners and a community of practice by which these pioneers of the IT frontier can share notes, insights, scripts and models - all in the service of the need to have more of a collective knowledge and a collective knowledge management of all of this new information that quite literally gets created every day.

Could you speak to the social dimension and this notion of peer-practitioner communities emerging?

IG: You are absolutely right on target. More than you could ever imagine. I think part of the education - and really today, that education has to be not only provided by the vendors and the system integrators, but by customers themselves - by the practitioners.

I think the game is going to be all about enabling customers to learn these things among themselves. This notion of community is critical. It's amazing that you're using the term, "IT Frontier," to describe that.

We very strongly believe in communities. We have our international community at bpms. intalio.com for the overall community of users of our product. But we are encouraging our partners to create local communities that essentially replicate what we are doing for our local market.

We have one in Japan that was announced two weeks ago that was created by none other than IT Frontier, which is the system integrator for Mitsubishi. They've created the Japanese community using - of course - Japanese characters, to essentially develop the usage and the understanding of the technology in Japan.

Here I'm spilling the beans on something that we're going to announce in a couple of months, but I think it's very appropriate to share it with you today. The creation of what we would call "micro" communities.
We have a hybrid commercial open-source business model. There's a version of our software that's free and that we call the "Community" edition. Then there's one that's paid by customers when they want more advanced enterprise features.

The Community edition is used today by about 30,000 companies around the world. We have a way of tracking that with a heart-beat mechanism. We know whenever customers deploy new processes; they can of course turn that mechanism off. But usually they don't. They're fine with sharing that information with us.

We found that in many of these organizations, we get different people using the software, but not knowing about each other and about each other's use of the software. We've been thinking about this issue. We came to the conclusion that we need to help these customers network internally, to share the knowledge of what they're doing, but to do that not necessarily in a completely public

fashion - because they might work with issues that are confidential. We're creating these micro-communities that are restricted to these particular accounts. And we're inviting all the people who've been using our software to join these communities. They can keep this information private or share only with external partners so that we do not disclose their work with us publicly or semi-publicly until they've agreed to.

Essentially, these communities or these microcommunity websites are made of forums and platforms where they can share documents and we can have multiple blogs. Essentially, we just facilitate this discussion. We enable people to discover each other and to discover what they do.

Then eventually you get management and upper management realizing that - "Gee - there is quite significant usage of this technology. It's starting to work in many parts of the organization. Maybe we should do something about it and get a little bit more serious about it. Maybe we should send a team for training. Maybe we should get a subscription for the software. Let's really keep an eye on that." MM: That's a brilliant summation of what I call "Open Source," marketing.

IG: That's exactly what it is. 
MM: We've found that in that context it's really important to have a good way of profiling the current state as an extended offer to the community. So think of it as a LinkedIn profile or a Facebook profile. So that when you visit a Facebook or a LinkedIn page - I know instantly two or three things that we might connect on as a topic of conversation.

IG: I agree. I totally agree.

MM: It turns out that another thing we've discovered is really fascinating. Especially for some of these larger, complex, integrated systems. Whether they're in the marketing operations or the content operations side.

In really large firms - we have found that independent master-class consultants oftentimes direct a large organizational transformational initiative or become the technical specifier. These become what we call Master Class Ronin Consultants, in that they're highly effective, "getting things done" consultants that have no problem getting a little blood on the floor. But at the end of the day, their business model is really simple. They sell an inventory of 210 days at $\$ 1,500$ a day.

Their issue is, "How much of that inventory can I sell into an organization running these projects?"

It turns out that in these little communities of practice, a certified consultant's program that facilitates trusted introductions to an otherwise well-funded project team - needs to have this consultant come in and basically get things done.

Have you seen evidence of the notion of this independent consultant playing a role in some of the larger projects that you've run?

IG: Yes. Very significantly. Both working on behalf of large corporations as well as government entities - which was kind of surprising to us.

MM: That makes even more sense.

IG: We've seen it in many different countries. For example, in the case of Con Edison, a utility company in New York that provides all the electricity for Manhattan, a lot of that work is being done by an independent consultant who is actually a professor at Columbia University. He now works for several different utility companies to do exactly this kind of engagement.

We've seen the very same in Australia - a consultant who works on e-government processes to automate the process of dealing with real-estate properties. As an Australian citizen, you need to interact with 15 different government agencies. It's a very complex process.

They use our software to integrate and automate all that and provide essentially a single unified portal with very simple workflows to the citizens. A lot of the work has been led by a university out there, with a couple of these kind of Ronin consultants that are wearing multiple hats and working for different customers.

We've also seen it a lot recently in financial services - especially at broker and dealer firms on Wall Street - for leading a lot of projects around SOA. And how SOA is going to support a lot of GRC projects. A lot of governance-riskmanagement and compliance projects.

Really, the question I would have back to you is, "Where do you find these people? Do you have groups that federate them? How do you get in touch with them?"

MM: Regarding these large teams - this tends to happen under the radar across a large organization. You could call them "micro" communities, or "micro" academies — peer-led learning events.

Would you speak to the notion of digital supply chains and some of the challenges and breakthroughs that you've had in terms of provisioning 100 per cent digital supply chains? IG: We're seeing a couple of things. I think one key element is the standardization of a lot of the tools and technologies that companies can use to build these digital supply chains. The reason for that is a lot of these supply channels are extended supply chains that are not managed by one party.

MM: Almost by definition, supply chains consist of many loosely coupled systems that pass data among themselves.

IG: That's exactly right.

I think the tipping point was reached when people realized that it's a lot easier to share when what you share is online in the cloud versus on your laptop's hard drive or in your data center that's protected by so many layers of firewalls.

More and more of the extended digital supply chain projects that we're seeing are being built in such a fashion that you've got a collection of online repositories and online systems in the clouds that are connected to each other to enable that. That's 
making everything easier by an order of magnitude, essentially.

The second thing that we are seeing is very much the realization by government customers both local and federal that these technologies are working - and that can enable them to better serve their constituency - especially the citizens - at a lower cost. It started with either emerging economies or new economies. But now we are starting to see that more and more in older industrial economies.

So what you would see five or ten years ago being leading-edge projects coming out of countries like Korea or Singapore, now we're starting to see the most advanced projects coming out of countries like Italy, for example. There, I've got in mind this particular example of the utility company in the city of Milan. It's serving about a million customers. It's deploying these meters for gas, water and electricity. It's connecting this meter to data centers through wireless technologies like cell phones, essentially - and doing that with a lot of local data centers. Then, harvesting all that information all the way back up to a central data center. And automating, of course, all the metering process, but also the maintenance and repair process for these meters onsite.

Connecting back to the people - the workers - the technicians that would install them and repair them.

Of course, then connecting back to the banking institutions for lowering the payments on these bills. Here, the most interesting implementations that I've seen are in Morocco, with a local subsidiary of LYDEC - the utility company based in Casa Blanca. Here, they're serving two million people, and they've deployed very interesting supply chains for actually doing the billing and the collection of the utility bills here for - I believe - water and garbage. They have very advanced technologies for collecting payment by credit card, but also very low-key implementations with people going door-todoor and collecting cash, and then going to an ATM to put that cash back into the system in a reliable and fast manner.

When you look at it from that viewpoint, you essentially have an almost entirely digital process. Manual work is only at the very end for the last mile or yard, I'd say, whenever it's the only way to do it.
MM: This reminds me of two other facets of digital supply chains that emerge as both fascinating and strategic.

One entails what I call the federated workmanagement dashboard. Essentially, it's browserbased. But it has an Ajax presentation capability. Graphs and bar charts and gauges, to visually telegraph to the worker what they need to do and what time-frame they need to do it in.

Because it's data federated in from an orchestration capability, the organization has the ability to dynamically re-allocate resources and dynamically task or retask resources as needed by a particular business contingency.

The other facet I would call "process orchestration." That is, the ability to orchestrate the activities and workflows and processes through an entire operation if not a supply chain. Could you speak to either as expressions of this digital supply chain vis-à-vis DPM? IG: Absolutely. What we're seeing now is this kind of scenario that you described as being in the past successfully implemented for very specific applications, using completely ad hoc tools and building custom applications for them.

Examples of that would be in the automation of a call center. You get very, very advanced load-balancing processes for balancing the work across work areas. And variances of reporting processes and reporting dashboards - to see how you're doing and what your SLA is and other things of that nature.

I think the next frontier - to use your terminology - is in providing a platform. We call that a business process platform. Providing a platform that can enable any customer to build this kind of environment for virtually any kind of business process - and to do that in a very cost-effective manner.

I don't know that any product does it to the extent that you described for any one process, and does it in such a way that small, medium and large corporations could deploy it. But I very strongly believe that we're getting there, and we're getting there fast.

The orchestration of the process - the technology to orchestrate the process - is there. The technology to serve these very dynamic, very user-friendly user interfaces - using Ajax - is there. The technology for doing load balancing of work among people is there. 
What's more difficult is in doing this load balancing of work for the work that is not transactional. It's much more related to knowledge. It's softer. It's a little bit less actionable. That's where a lot of thinking has to be done in understanding how you can not only deal with the transactional side of things, but also the creative side of the process. Essentially, doing load balancing of work in a creative process - and mixing the two.

MM: I have run across a couple of applications that have begun to do exactly that. In terms of the activity stages, ideation and creation usually entail a highly collaborative, circular set of communications and interactions focusing or emphasizing discovery.

Then as soon as the discovery gets ideated and created and funded, it then shifts its process model from collaboration to workflow - which tends to be much more procedural, gated and time-specific. Correct?

IG: We've found that the underlying systems to facilitate both the collaborative and the procedural entail routing, forms and business rules modeling.

Those three things enable you to create dashboards for the creative team by which to keep track of the ideation process. If you're using collaboration tools like Vyew, you can now have the back-end vis-à-vis a SOAP interface - activity data in terms of what's going on inside each of the Vyew workspaces. MM: We've been seeing that, but it ultimately comes down to a set of technologies of routing, forms, business rules with a really good presentation layer.

IG: I agree with you. Those are the fundamental building blocks. There are several products that do that today. The ones I know always require that you specify the process in a quite formal fashion ahead of time.

I think the next frontier is in doing not only these, but also enabling a much more ad hoc way of creating the process. And doing that, of course, through tools that are usable by the nontechnical users or at least the less-technical users.

A lot of these tools exist today to deal with data. For example, if you take a look at a product like Salesforce.com, which people think of as strictly customer-relationship management tools - I actually believe it's much more than that. It's essentially a generic database development tool that has such easy-to-use tools that nontechnical people can essentially build any kind of data model they want.

The application is essentially a by-product of your data-modeling exercise. You can build very interesting scenarios. But it's a very datacentric platform. It solves very data-centric problems.

We need an equivalent of that in a processcentric manner. I think a lot of - here in that case - invention, creation and ideation has to be done by the industry at large to get there. But that's very much the vision that's taking us forward.

MM: Right.

Can you speak to some of the critical factors in terms of putting together an enterprise taskforce for a large BPM project?

IG: I think education is where it all begins. It's going to be - as you said - a large project. You need to know what you're doing. You need to understand the tools that you're going to leverage. You need to select the right tool for the job. You cannot do that if you're not educated enough about this space.

I think education and training is the absolute first step in doing that. Especially if you believe in the power of self-empowerment - if you want to be in charge of your own destiny.

That's also an area where I believe these Samurais that we talked about before can play a very key role. You're going to rely on them to be your coach and mentor throughout this journey. They're going to help you. They're going to transfer a lot of their knowledge. They're going to facilitate the process in many ways.

So I would very strongly recommend that indeed you bring one or several of them, as opposed to taking the business problem that you have and giving it away to a system-integration partner that - again — will not allow you to learn anything about the way to solve business problems.

I think the second element is, you need to involve the different stakeholders. It sounds trivial, but I think many projects fail because they are not involving enough of the stakeholders that should be represented. I'm thinking the technical people and the business people. On the business side, you've got the process owner and the end users. 
Many of the people - based on the context - should have a say about the problem to solve and the way you're going to solve it. In many cases, that's where it becomes much more difficult. Those stakeholders live outside of the organization. They're partners. They're customers. They're consultants. Here, involving them in this project is a lot more difficult. That's where using the tools that you mentioned that live in the cloud as opposed to being in your data center or on your laptop is going to be key. But I think the technical side of the story is only the easy part. Technology is easy. What's difficult is people and culture. Organizations. Dealing with change. The fear of change.
It's even more difficult when you do that throughout an extended value chain, where multiple parties need to be aligned. So, here my advice would be, "Don't try to do too much too fast. Especially until you've learned some lessons about what's working and what's not."

You might want to start with slightly smaller projects with lower-hanging fruits. Learn along the way. Get first successes under your belt. Then be a little bit more ambitious. Walk before you run. Right now, I think we're at the crawling stage, to be honest.

MM: Ismael, I want to thank you again for the interview. 